\title{
A METHOD FOR DETERMINING STOICHIOMETRIC COEFFICIENTS USING MINORS OF A MATRIX
}

\author{
Rainier Lombaard
}

Email: rlombaard.ac@gmail.com

\begin{abstract}
Spinel materials often have complex structures and as a result, balancing of reactions with these compounds by traditional methods become very time consuming. A method to calculate the stoichiometric coefficients for chemical reactions using first a modified matrix-inverse method and then an optimised method is proposed. Both methods are explored using linear algebra and the result demonstrated using a typical chromite reduction reaction.
\end{abstract}

\section{Introduction}

One of the first concepts that students of chemistry learn is that of conservation of mass. Physical changes that demonstrate that mass is conserved during phase change are typically demonstrated, after which chemical reactions are introduced. In a chemical reaction the mass and elements are still conserved but the initial substances, reactants, will be transformed into new substances, products. In pioneering work done during the late 1700's, Antoine Lavoisier showed conclusively that the law of conservation of mass also applies to chemical reactions with the publication of his Traite élémentaire de chimie "In all the operations of art and nature, nothing is created; an equal quantity of matter exists both before and after the experiment; the quality and quantity of the elements remain precisely the same." (Lavoisier, 1789).

It was then understood that since the quantities of each element cannot change, even though they would form part of different substances, the amounts of reactants and products must be scaled by integer coefficients for the law of conservation of mass to hold (IUPAC, 1997). This insight led to the development of stoichiometry which studies the relationship between the amounts of reactants consumed and products produced in chemical reactions (Brown et al, 2015). As demonstration, consider the hypothetical single displacement reaction below:

$$
x_{1} A_{a} B_{b}+x_{2} C_{c} \rightarrow x_{3} A_{d} C_{e}+x_{4} B_{f}
$$

The stoichiometric coefficients $x_{1}, x_{2}, x_{3}$ and $x_{4}$ must be some integers such that the number of atoms of elements $A, B$ and $C$ are the same on both sides of the arrow. The dominant method taught at high school and even university level to find the values of the coefficients is solving by inspection (Toth, 1997). This casual approach works well with simple chemical equations such as the one shown above. But for even slightly more complex reactions involving larger quantities of reactants and products, this inspection method becomes slow and unreliable.

Most students of chemistry would also be familiar with linear algebra and its techniques. To demonstrate some of the applications of linear algebra, systems of linear equations are introduced and then applied to chemical equations. This algebraic method of using a matrix of coefficients results in a much more systematic approach to balancing chemical equations and with the advent of modern scientific calculators that can store and manipulate matrices, has become the standard. However, this system of equations method becomes cumbersome to work with for large reaction equations with many substances and elements. Therefore, it is the goal is to develop a general method that can be applied to all chemical equations with ease. 


\section{Discussion}

This project came about during the study of metallothermic reduction of metal oxide ores. These ores typically consist of complicated mineral structures which, when undergoing reduction, become very burdensome to balance by hand. Consider the following chromite molecule and its subsequent reduction with aluminium:

$$
x_{1}\left(M_{0.44} \mathrm{Fe}_{0.55}\right)\left(\mathrm{Cr}_{1.36} \mathrm{Al}_{0.55} \mathrm{Fe}_{0.08}\right)_{2} \mathrm{O}_{4}+x_{2} \mathrm{Al} \rightarrow x_{3} \mathrm{Mg}+x_{4} \mathrm{Fe}+x_{5} \mathrm{Cr}+x_{6} \mathrm{Al}_{2} \mathrm{O}_{3}
$$

It is readily apparent that solving the following by inspection would be a very time-consuming task. However, below we outline a new augmented matrix method to calculate the coefficients using a simple spreadsheet application with ease.

\section{Methodology}

The steps that can be followed to solve the stoichiometric coefficients are outlined below:

1) Construct a composition array for the reaction

2) From this array extract the coefficient matrix $K_{i j}$

3) Construct the augmented matrix $A_{n m}$ according to the following rules:

- If $n \leq i$ and $m \leq j$ then $a_{n m}=c_{i j}$

- If $n>i$ and $m \leq j$ insert the reversal matrix $J_{a j}$

- If $n>i$ and $m>j$ insert the null matrix $0_{a d}$

- If $n=i$ and $m>j$ insert the matrix [ $\left.\begin{array}{cccc}1 & 0 & \cdots & 0_{1 d}\end{array}\right]$

- If $n \leq i-1$ and $m>j$ insert reversal matrix $J_{(i-1) d}$ with first column of zeros

- Where $k=\operatorname{Max}(i, j)-\operatorname{Min}(i, j)$ then $a=i+k+2$ and $d=j+k+2$

4) Extract the final coefficient matrix $B_{x y}$ such that $x=y$ according to the rules:

- If $i<j$ then $x=i+k$ and $y=j$ or,

- If $i>j$ then $x=i+1$ and $y=j+k+1$ or,

- If $i=j$ then $x=i+1$ and $y=j+1$

5) Determine the inverse matrix $B_{x y}{ }^{-1}$ as well as the determinant $\operatorname{det}\left(B_{x y}\right)$

6) Transpose the last column of $B_{x y}{ }^{-1}$ into a new matrix $C_{1 n}$

7) Multiply $C_{1 n}$ by the absolute value of the determinant, $\left|\operatorname{det}\left(B_{x y}\right)\right| \cdot C_{1 n}=D_{1 n}$

8) Divide each element of $D_{1 n}$ the greatest common divisor, $D_{1 n} / \operatorname{gcd}\left(d_{11}, \cdots, d_{1 n}\right)=E_{1 n}$

9) The resulting matrix $E_{1 n}$ now contains the stoichiometric coefficients from left to right.

The above method may seem needlessly complex, but the repeatability will become readily apparent. In the final section of the paper an optimised method for determining the stoichiometric coefficients is revealed. First, we will demonstrate the above methodology using a simple double displacement reaction:

\section{The reaction of iron(III) oxide with sulfuric acid}

$$
x_{1} \mathrm{Fe}_{2} \mathrm{O}_{3}+x_{2} \mathrm{H}_{2} \mathrm{SO}_{4} \rightarrow x_{3} \mathrm{Fe}_{2}\left(\mathrm{SO}_{4}\right)_{3}+x_{4} \mathrm{H}_{2} \mathrm{O}
$$




\section{Step 1}

Construct a composition array for the reaction:

\begin{tabular}{c|cccc} 
& $\mathrm{Fe}_{2} \mathrm{O}_{3}$ & $\mathrm{H}_{2} \mathrm{SO}_{4}$ & $\mathrm{Fe}_{2}\left(\mathrm{SO}_{4}\right)_{3}$ & $\mathrm{H}_{2} \mathrm{O}$ \\
\hline $\mathrm{Fe}$ & 2 & 0 & -2 & 0 \\
$O$ & 3 & 4 & -12 & -1 \\
$\mathrm{H}$ & 0 & 2 & 0 & -2 \\
$S$ & 0 & 1 & -3 & 0
\end{tabular}

Note that the coefficients for the products are all assigned the negative value. This is a direct consequence of the law of conservation of mass since the quantity of any element needs to add to zero on both sides of the chemical equation. This is usually the method employed when using a system of linear equations to determine the coefficients (Gabriel et. al, 2015).

\section{Step 2}

From this array we then extract the matrix $\mathrm{K}$ :

$$
K=\left[\begin{array}{cccc}
2 & 0 & -2 & 0 \\
3 & 4 & -12 & -1 \\
0 & 2 & 0 & -2 \\
0 & 1 & -3 & 0
\end{array}\right]
$$

\section{Step 3}

Construct the augmented matrix A:

$$
\begin{gathered}
i=j=4 \\
\therefore a=d=6 \\
A=\left[\begin{array}{cccccc}
2 & 0 & -2 & 0 & 0 & 0 \\
3 & 4 & -12 & -1 & 0 & 1 \\
0 & 2 & 0 & -2 & 0 & 0 \\
0 & 1 & -3 & 0 & 1 & 0 \\
0 & 0 & 0 & 1 & 0 & 0 \\
0 & 0 & 1 & 0 & 0 & 0
\end{array}\right]
\end{gathered}
$$

\section{Step 4}

Extract the coefficient matrix B:

$$
\begin{gathered}
i=j=4 \\
\therefore x=y=5 \\
B=\left[\begin{array}{ccccc}
2 & 0 & -2 & 0 & 0 \\
3 & 4 & -12 & -1 & 0 \\
0 & 2 & 0 & -2 & 0 \\
0 & 1 & -3 & 0 & 1 \\
0 & 0 & 0 & 1 & 0
\end{array}\right]
\end{gathered}
$$




\section{Step 5}

Determine the inverse matrix $B^{-1}$ as well as the determinant:

$$
B^{-1}=\left[\begin{array}{ccccc}
\frac{2}{3} & -\frac{1}{9} & \frac{2}{9} & 0 & \frac{1}{3} \\
0 & 0 & \frac{1}{2} & 0 & 1 \\
\frac{1}{6} & -\frac{1}{9} & \frac{2}{9} & 0 & \frac{1}{3} \\
0 & 0 & 0 & 0 & 1 \\
\frac{1}{2} & -\frac{1}{3} & \frac{1}{6} & 1 & 0
\end{array}\right] \text { and } \operatorname{det}(B)=-36
$$

\section{Step 6}

Transpose the last column of $B^{-1}$ into a new matrix D:

$$
C=\left[\begin{array}{lllll}
\frac{1}{3} & 1 & \frac{1}{3} & 1 & 0
\end{array}\right]
$$

\section{Step 7}

Multiply D by the absolute value of the determinant:

$$
|-36| \cdot C=D=\left[\begin{array}{lllll}
12 & 36 & 12 & 36 & 0
\end{array}\right]
$$

\section{Step 8}

Divide each element of $\mathrm{E}$ the greatest common divisor:

$$
\operatorname{gcd}\left(d_{11}, \cdots, d_{15}\right)=12 \quad \therefore E=\left[\begin{array}{lllll}
1 & 3 & 1 & 3 & 0
\end{array}\right]
$$

And therefore, $x_{1}=x_{3}=1$ and $x_{2}=x_{4}=3$ resulting in the balanced chemical equation:

$$
\mathrm{Fe}_{2} \mathrm{O}_{3}+3 \mathrm{H}_{2} \mathrm{SO}_{4} \rightarrow \mathrm{Fe}_{2}\left(\mathrm{SO}_{4}\right)_{3}+3 \mathrm{H}_{2} \mathrm{O}
$$




\section{Mathematical Background}

To fully understand why the method above yield the stoichiometric coefficients we can explore the mathematics behind the method in greater detail. Consider the following hypothetical double displacement reaction:

$$
x_{1} A_{a} B_{b}+x_{2} C_{c} D_{d} \rightarrow x_{3} A_{o} D_{p}+x_{4} C_{q} B_{r}
$$

Setting up the composition array at the coefficient matrix:

$$
\begin{array}{c|cccc} 
& A_{a} \mathrm{~B}_{b} & C_{c} D_{d} & A_{o} D_{p} & C_{q} B_{r} \\
\hline A & a & 0 & -o & 0 \\
B & b & 0 & 0 & -q \\
C & 0 & c & 0 & -r \\
D & 0 & d & -p & 0
\end{array} \text { and then } K=\left[\begin{array}{cccc}
a & 0 & -o & 0 \\
b & 0 & 0 & -q \\
0 & c & 0 & -r \\
0 & d & -p & 0
\end{array}\right]
$$

Supposing that the steps to augment the matrix are not followed and the matrix-inverse method is directly applied. The inverse of $\mathrm{K}$ can then be found by multiplying the transposed cofactor matrix $\mathrm{C}^{\mathrm{T}}$ with the inverse of the determinant of $\mathrm{K}$ :

$$
\begin{aligned}
K^{-1} & =\operatorname{det}(K)^{-1} \operatorname{adj}(K)=\frac{1}{\operatorname{det}(K)} C^{T} \\
& =\frac{1}{a c p q-b d o r} C^{T}
\end{aligned}
$$

The problem encountered with chemical reactions that yield square coefficient matrices from the start is that the determinant is always zero i.e. $\operatorname{det}(K)=0$ such that matrix $\mathrm{K}$ is degenerate and not invertible. This can easily be shown by using the composition matrix and the traditional method for solving the stoichiometric coefficients by using a system of equations:

$$
\mathrm{Kx}=0 \rightarrow\left[\begin{array}{cccc}
a & 0 & -o & 0 \\
b & 0 & 0 & -q \\
0 & c & 0 & -r \\
0 & d & -p & 0
\end{array}\right]\left[\begin{array}{l}
x_{1} \\
x_{2} \\
x_{3} \\
x_{4}
\end{array}\right]=\left[\begin{array}{l}
0 \\
0 \\
0 \\
0
\end{array}\right]
$$

It is immediately apparent that if $\mathrm{Kx}=0$ then the column vector $\mathrm{x}$ must be equal to zero as well. Furthermore, it can be conclusively demonstrated that $\operatorname{det}(K)=0$ by setting up the system of linear equations from the above and solving them simultaneously:

$$
\begin{array}{r}
a x_{1}-o x_{3}=0 \\
b x_{1}-q x_{4}=0 \\
c x_{2}-r x_{4}=0 \\
d x_{2}-p x_{3}=0
\end{array}
$$




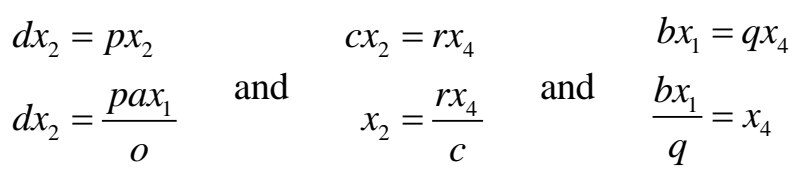

$$
\begin{aligned}
& \text { so that } d\left(\frac{r x_{4}}{c}\right)=\frac{\text { pax }_{1}}{o} \text { becomes } \frac{d r}{c}\left(\frac{b x_{1}}{q}\right)=\frac{\operatorname{pax}_{1}}{o} \\
& \text { and then } \frac{d r b}{c q}=\frac{p a}{o} \\
& d r b o=p a c q \\
& a c p q-b d o r=0
\end{aligned}
$$

Revealing that determinant of the square coefficient matrix is indeed zero. If the equation is viewed carefully and keeping in mind that the column vector $\mathrm{x}$ is zero, we can see why this occurs. Reaction equations can be balanced in an infinite number of ways, and therefore do not have a single unique solution, for example:

$$
\begin{array}{lccc}
\mathrm{Fe}_{2} \mathrm{O}_{3} & +3 \mathrm{H}_{2} \mathrm{SO}_{4} & \rightarrow \mathrm{Fe}_{2}\left(\mathrm{SO}_{4}\right)_{3} & +3 \mathrm{H}_{2} \mathrm{O} \\
2 & 6 & 2 & 6 \\
3 & 9 & 3 & 9 \\
\vdots & \vdots & \vdots & \vdots
\end{array}
$$

The algebraic method is still a step up from solving by inspection and the coefficients can be solved by hand if only a few equations are present or by making use of a suitable software package, such as Matlab, (Gabriel et. al, 2015). This is achieved by finding the row echelon form of the augmented matrix $\mathrm{K}$ and solving the subsequent system of equations. However, as the complexity of reaction equations increases so does the effort required to solve by row echelon form.

It is therefore apparent that a better method is needed to approach these problems by making use of the tools available to modern scientific calculators which almost every chemistry student will be equipped with. The steps outlined in the first section allows us to construct an invertible matrix such that $\operatorname{det}(B) \neq 0$. Let us now repeat the first hypothetical reaction with this method:

$$
B=\left[\begin{array}{ccccc}
a & 0 & -o & 0 & 0 \\
b & 0 & 0 & -q & 0 \\
0 & c & 0 & -r & 0 \\
0 & d & -p & 0 & 1 \\
0 & 0 & 0 & 1 & 0
\end{array}\right] \text { and } B^{-1}=\left[\begin{array}{ccccc}
0 & \frac{1}{b} & 0 & 0 & \frac{q}{b} \\
0 & 0 & \frac{1}{c} & 0 & \frac{r}{c} \\
-\frac{1}{o} & \frac{a}{b o} & 0 & 0 & \frac{a q}{b o} \\
0 & 0 & 0 & 0 & 1 \\
-\frac{p}{o} & \frac{a p}{b o} & -\frac{d}{c} & 1 & \frac{a c p q-b d o r}{b c o}
\end{array}\right]
$$


Now we have that $\operatorname{det}(B)=b c o$ and then computing matrix D:

$$
\begin{aligned}
D & =\left[\begin{array}{lllll}
c o q & \text { bor } & \text { acq } & \text { bco } & \text { acpq-bdor }
\end{array}\right] \\
& =\left[\begin{array}{lllll}
c o q & \text { bor } & \text { acq } & \text { bco } & 0
\end{array}\right]
\end{aligned}
$$

Depending on the values of $d_{11}-d_{14}$ we potentially have to divide by $\operatorname{gcd}\left(d_{11}, \cdots, d_{14}\right)$ if necessary, so that the lowest stoichiometric coefficients are obtained in matrix $\mathrm{E}$. The validity of this result can be demonstrated by using another system of linear equations:

$$
\mathrm{Kx}=0 \rightarrow\left[\begin{array}{ccccc}
a & 0 & -o & 0 & 0 \\
b & 0 & 0 & -q & 0 \\
0 & c & 0 & -r & 0 \\
0 & d & -p & 0 & 1 \\
0 & 0 & 0 & 1 & 0
\end{array}\right] \cdot\left[\begin{array}{c}
x_{1} \\
x_{2} \\
x_{3} \\
x_{4} \\
k_{1}
\end{array}\right]=\left[\begin{array}{l}
0 \\
0 \\
0 \\
0 \\
z
\end{array}\right]
$$

Yielding a slightly modified version of the set of equations found in the first instance:

$$
\begin{aligned}
a x_{4}-o x_{3} & =0 \\
b x_{1}-q x_{4} & =0 \\
c x_{2}-r x_{4} & =0 \\
d x_{2}-p x_{3}+k_{1} & =0 \\
x_{4} & =x_{4}
\end{aligned}
$$

It can now be seen that the reason for the augmentation with reversal matrices. as per step 3 of the methodology, is that the coefficients $k_{1}, k_{2} \cdots k_{i}$ will be equal to zero and several trivial equations such as $x_{4}=x_{4}$ will result. This way the augmentation does not change the meaning of the original equation itself and therefore is mathematically sound. Solving the above equations:

$$
\begin{aligned}
k_{1} & =p x_{3}-d x_{2} \\
& =p\left(\frac{a x_{1}}{o}\right)-d\left(\frac{r x_{4}}{c}\right) \\
& =\frac{x_{4}(a c p q-b d o r)}{o b c} \\
o b c \cdot k_{1} & =x_{4}(a c p q-b d o r)
\end{aligned}
$$


However, we have that $x_{1}, x_{2}, x_{3}, x_{4} \neq k_{i}=0$ and from the earlier example $\operatorname{det}(K)=a c p q-b d o r=0$ and therefore we can conclude that:

$$
\begin{aligned}
& (o b c) \cdot k_{1}=x_{4}(a c p q-b d o r) \\
& (o b c) \cdot k_{1}=x_{4}(0)
\end{aligned}
$$

From which it follows that $x_{4}=o b c$ leading to:

$$
\begin{aligned}
& x_{1}=\frac{q x_{4}}{b} \quad x_{2}=\frac{r x_{4}}{c} \quad x_{3}=\frac{a x_{1}}{o} \\
& =\frac{q \cdot o b c}{b} \text { and }=\frac{r \cdot o b c}{c} \text { and }=\frac{a \cdot c o q}{o} \\
& =c o q \quad=r o b \quad=a c q
\end{aligned}
$$

Therefore $x_{1}=c o q ; x_{2}=b o w ; x_{3}=a c q ; x_{4}=b c o ; k_{1}=a c p q-b d o r$ as expected.

In general this method should work for all chemical equations. Focusing on the matrix of minors:

$$
M=\left[\begin{array}{cccc}
M_{11} & M_{12} & \cdots & M_{1 j} \\
M_{21} & M_{22} & \cdots & M_{2 j} \\
\vdots & \vdots & \ddots & \vdots \\
M_{i 1} & M_{n 2} & \cdots & M_{i j}
\end{array}\right]
$$

Since the first row of a composition matrix for any chemical reaction cannot be all zeros, in fact it must contain at least two non-zero elements, the minors in the $\mathrm{i}^{\text {th }}$ row will not be equal to zero. Furthermore, if the augmentation is done according to the methodology, this will lead to the minors of the $\mathrm{i}^{\text {th }}$ row containing only elements from the original composition array. These two propositions can be demonstrated by using simple Laplace expansion:

$$
\text { If } A=\left[\begin{array}{lll}
a_{11} & a_{12} & a_{13} \\
a_{21} & a_{22} & a_{23} \\
a_{31} & a_{32} & a_{33}
\end{array}\right] \text { the } B=\left[\begin{array}{cccc}
a_{11} & a_{12} & a_{13} & 0 \\
a_{21} & a_{22} & a_{23} & 0 \\
a_{31} & a_{32} & a_{33} & 1 \\
0 & 0 & 1 & 0
\end{array}\right] \text { with } M_{11}=\left|\begin{array}{ccc}
a_{22} & a_{23} & 0 \\
a_{32} & a_{33} & 1 \\
0 & 1 & 0
\end{array}\right|=-a_{22}
$$

and so forth for all minors until the matrix of minors is found: 


$$
M=\left[\begin{array}{cccc}
-a_{22} & -a_{21} & 0 & a_{21} a_{32}-a_{22} a_{31} \\
-a_{12} & -a_{11} & 0 & a_{11} a_{32}-a_{12} a_{31} \\
0 & 0 & 0 & a_{11} a_{22}-a_{12} a_{21} \\
a_{12} a_{23}-a_{13} a_{22} & a_{11} a_{23}-a_{13} a_{21} & a_{11} a_{22}-a_{12} a_{21} & \operatorname{det}(A)
\end{array}\right]
$$

This assumed a square composition matrix as starting point, but the above method holds for the other 2 types of matrices as per step 3 of the methodology as well. Additional examples as well as possible real-life applications are shown in Appendix A. Re-examining the earlier equation and matrix $\mathrm{K}$, the minors of $\mathrm{K}$ become:

$$
M=\left[\begin{array}{ccccc}
0 & 0 & -b d & 0 & -b d p \\
-c o & 0 & -a c & 0 & -a c p \\
0 & -b o & 0 & 0 & -b d o \\
0 & 0 & 0 & 0 & -b c o \\
c o q & -b o r & a c q & -b c o & a c p q-b d o r
\end{array}\right]
$$

Notice that the last row of minors yields the stoichiometric coefficients and indeed only contain elements from the composition array. This is a result of step 5-7 in the methodology, where we multiplied the previous result with the $\operatorname{det}(B)$ :

$$
\begin{aligned}
B^{-1} & =\frac{1}{\operatorname{det}(B)} C^{T} \\
\operatorname{det}(B) \times B^{-1} & =C^{T}
\end{aligned}
$$

Since $\mathrm{C}^{\mathrm{T}}$ is found by the minors $C_{i j}=(-1)^{i+j} M_{i j}$ a more efficient modified method is now revealed. Follow steps $1-4$ as before but then instead of determining the inverse of the matrix $\mathrm{B}$, calculate and use the absolute values of the minors of the $\mathrm{y}^{\text {th }}$ row of $\mathrm{B}$ only and then dividing each element by the greatest common divisor, if necessary:

$$
\begin{gathered}
D=\left[\begin{array}{lllll}
c o q & \text { bor } & \text { acq } & \text { bco } & \operatorname{det}(K)
\end{array}\right] \\
\frac{D}{\operatorname{gcd}(D)}=E=\left[\begin{array}{lllll}
\operatorname{coq} & \text { bor } & \text { acq } & \text { bco } & 0
\end{array}\right]
\end{gathered}
$$

This new method yields the same stoichiometric coefficients in far fewer steps and since the tools available to chemistry students enable them to calculate determinants with relative ease, find the minors in last row becomes a relatively trivial task. 


\section{Reduction of Chromite with Aluminium}

Let us return our attention now to the original problem presented by the reduction reaction of chromite.

$$
x_{1}\left(\mathrm{Mg}_{0.44} \mathrm{Fe}_{0.55}\right)\left(\mathrm{Cr}_{1.36} \mathrm{Al}_{0.55} \mathrm{Fe}_{0.08}\right)_{2} \mathrm{O}_{4}+x_{2} \mathrm{Al} \rightarrow x_{3} \mathrm{Mg}+x_{4} \mathrm{Fe}+x_{5} \mathrm{Cr}+x_{6} \mathrm{Al}_{2} \mathrm{O}_{3}
$$

We will now solve the stoichiometric coefficients using the cofactors only and using the matrixinverse method below:

\begin{tabular}{c|cccccc} 
& $\begin{array}{c}\left(\mathrm{Mg}_{0.44} \mathrm{Fe}_{0.55}\right) \\
\left(\mathrm{Cr}_{1.36} \mathrm{Al}_{0.55} \mathrm{Fe}_{0.08}\right)_{2} \mathrm{O}_{4}\end{array}$ & $\mathrm{Al}$ & $\mathrm{Mg}$ & $\mathrm{Fe}$ & $\mathrm{Cr}$ & $\mathrm{Al}_{2} \mathrm{O}_{3}$ \\
\hline $\mathrm{Mg}$ & 44 & 0 & -1 & 0 & 0 & 0 \\
$\mathrm{Fe}$ & 63 & 0 & 0 & -1 & 0 & 0 \\
$\mathrm{Cr}$ & 136 & 0 & 0 & 0 & -1 & 0 \\
$\mathrm{Al}$ & 55 & 1 & 0 & 0 & 0 & -2 \\
$\mathrm{O}$ & 397 & 0 & 0 & 0 & 0 & -3
\end{tabular}

From this array we then extract the matrix $\mathrm{K}$ :

$$
K=\left[\begin{array}{cccccc}
44 & 0 & -1 & 0 & 0 & 0 \\
63 & 0 & 0 & -1 & 0 & 0 \\
136 & 0 & 0 & 0 & -1 & 0 \\
55 & 1 & 0 & 0 & 0 & -2 \\
397 & 0 & 0 & 0 & 0 & -3
\end{array}\right]
$$

Construct the augmented matrix A according to the rules and extract the coefficient matrix B:

$$
B=\left[\begin{array}{cccccc}
44 & 0 & -1 & 0 & 0 & 0 \\
63 & 0 & 0 & -1 & 0 & 0 \\
136 & 0 & 0 & 0 & -1 & 0 \\
55 & 1 & 0 & 0 & 0 & -2 \\
397 & 0 & 0 & 0 & 0 & -3 \\
0 & 0 & 0 & 0 & 0 & 1
\end{array}\right]
$$

Determine the absolute minors $M_{61}-M_{66}$ :

$$
D=\left[\begin{array}{llllll}
3 & 629 & 132 & 189 & 408 & 397
\end{array}\right]
$$

Since $\operatorname{gcd}\left(d_{11}, \cdots, d_{15}\right)=1$ no additional steps are needed and we have the balanced equation:

$$
3\left(\mathrm{Mg}_{0.44} \mathrm{Fe}_{0.55}\right)\left(\mathrm{Cr}_{1.36} \mathrm{Al}_{0.55} \mathrm{Fe}_{0.08}\right)_{2} \mathrm{O}_{4}+629 \mathrm{Al} \rightarrow 132 \mathrm{Mg}+189 \mathrm{Fe}+408 \mathrm{Cr}+397 \mathrm{Al}_{2} \mathrm{O}_{3}
$$


Using the full augmented matrix-inversion method as described earlier. Determine the inverse matrix $B^{-1}$ as well as the determinant $\operatorname{det}(B)$ :

$$
B^{-1}=\left[\begin{array}{cccccc}
0 & 0 & 0 & 0 & \frac{1}{397} & \frac{3}{397} \\
0 & 0 & 0 & 1 & -\frac{55}{397} & \frac{629}{397} \\
-1 & 0 & 0 & 0 & \frac{44}{397} & \frac{132}{397} \\
0 & -1 & 0 & 0 & \frac{63}{397} & \frac{189}{397} \\
0 & 0 & -1 & 0 & \frac{136}{397} & \frac{408}{397} \\
0 & 0 & 0 & 0 & 0 & 1
\end{array}\right] \text { and } \operatorname{det}(B)=397
$$

Transpose the last column of $B^{-1}$ into a new matrix C:

$$
C=\left[\begin{array}{llllll}
\frac{3}{397} & \frac{629}{397} & \frac{132}{397} & \frac{189}{397} & \frac{408}{397} & 1
\end{array}\right]
$$

Multiply $\mathrm{C}$ by the absolute value of the determinant:

$$
|397| \cdot C=D=\left[\begin{array}{llllll}
3 & 629 & 132 & 189 & 408 & 397
\end{array}\right]
$$

Since $\operatorname{gcd}\left(d_{11}, \cdots, d_{15}\right)=1$ we again get the balanced equation:

$$
3\left(\mathrm{Mg}_{0.44} \mathrm{Fe}_{0.55}\right)\left(\mathrm{Cr}_{1.36} \mathrm{Al}_{0.55} \mathrm{Fe}_{0.08}\right)_{2} \mathrm{O}_{4}+629 \mathrm{Al} \rightarrow 132 \mathrm{Mg}+189 \mathrm{Fe}+408 \mathrm{Cr}+397 \mathrm{Al}_{2} \mathrm{O}_{3}
$$

Given the large values of the stoichiometric coefficients it would have taken a considerable amount of time to solve the reaction equation by inspection but using the new cofactor method the results was determined with ease.

\section{Conclusion}

Based on the need to quickly determine the stoichiometric coefficients of reaction equations, the proven, but slow, method of using a system of linear equations was expanded upon. The resulting procedure of setting up an augmented matrix and then determining minors results in an efficient and convenient method that can handle even large reaction equations with ease. 


\section{Acknowledgements}

I would like to thank Ryan Ball of CAMICO SA for generously supplying samples of chromite from their Johannesburg stockpile at no cost as well as providing valuable and experienced insight into the workings of the chromium industry in South Africa.

\section{References}

Lavoisier, A. Traité élémentaire de chimie. Paris, France: Cuchet, 1789.

IUPAC. Compendium of Chemical Terminology, 2nd ed.. Compiled by A. D. McNaught and A. Wilkinson. Blackwell Scientific Publications, Oxford, 1997.

Brown, T. LeMay H. Bursten, B. Murphy, C. Woodward, P. Stoltzfus, M. Chemistry: The Central Science, $13^{\text {th }}$ Ed. Pearson, 2015

Toth, Z. Balancing chemical equations by inspection. Journal Chemical Education, 74 (11), 1363. 1997.

Gabriel, C. Onwuka, G. Balancing of Chemical Equations Using Matrix Algebra. Journal of Natural Sciences Research. 2015

Schwab, B. Working with electron microprobe data from a high pressure experiment-Calculating mineral formulas, unit cell content and geothermomerty. Humboldt State University, 2019. 


\section{Appendix A \\ Mineral Structure of Chromite}

For the example above a sample of South African chromite concentrate was analysed at a SANAS accredited laboratory and found to have a composition of metal oxides by weight percent as seen in column two of table 1. The method as described by $(S c h w a b, 2019)$ was then used to calculate the mineral structure.

\begin{tabular}{lcccccccc}
$\begin{array}{c}\text { Oxides } \\
\text { Present }\end{array}$ & $\%$ w/w & $\begin{array}{c}\text { Cations } \\
\text { in Oxide }\end{array}$ & $\begin{array}{c}\text { Anions } \\
\text { in Oxide }\end{array}$ & $\begin{array}{c}\text { Molar } \\
\text { Mass }\end{array}$ & $\begin{array}{c}\text { Mol } \\
\text { Proportion }\end{array}$ & $\begin{array}{c}\text { Oxygen } \\
\text { Proportion }\end{array}$ & $\begin{array}{c}\text { Number } \\
\text { of } \\
\text { Anions }\end{array}$ & $\begin{array}{c}\text { Number } \\
\text { of } \\
\text { Cations }\end{array}$ \\
\hline $\mathbf{A l 2 O 3}$ & 13.94 & 2 & 3 & 101.961 & 0.137 & 0.410 & 0.831 & 0.554 \\
$\mathbf{F e 2 O 3}$ & 3.00 & 2 & 3 & 159.687 & 0.019 & 0.056 & 0.114 & 0.076 \\
$\mathbf{C r 2 O 3}$ & 51.10 & 2 & 3 & 151.990 & 0.336 & 1.009 & 2.044 & 1.363 \\
$\mathbf{F e O}$ & 19.57 & 1 & 1 & 71.846 & 0.272 & 0.272 & 0.552 & 0.552 \\
$\mathbf{C a O}$ & 0.40 & 1 & 1 & 56.077 & 0.007 & 0.007 & 0.014 & 0.014 \\
$\mathbf{M g O}$ & 8.84 & 1 & 1 & 40.311 & 0.219 & 0.219 & 0.444 & 0.444 \\
\hline & $\sum 96.85$ & & & & & $\sum 1.974$ & $\sum 4.000$ & $\sum 3.000$ \\
\hline
\end{tabular}

Oxygen Atoms in Structure:

Chromite is found as a spinel conforming to the general formula of $\mathrm{AB}_{2} \mathrm{O}_{4}$, where $\mathrm{A}^{2+}$ and $\mathrm{B}^{3+}$ denote the cations that occupy the tetrahedral and octahedral sites respectively (Weller, 2014). Typical chromite has the formula $\mathrm{FeCr}_{2} \mathrm{O}_{4}$ but the $\mathrm{Fe}^{2+}$ and $\mathrm{Cr}^{3+}$ cations are frequently replaced by other ions such as $\mathrm{Mg}^{2+}$ and $\mathrm{Al}^{3+}$ which can be clearly seen from the percentage compositions above. From the data it was calculated that the approximate structure of this specific sample of concentrate is $\left(\mathrm{Mg}_{0.44} \mathrm{Fe}_{0.55}\right)\left(\mathrm{Cr}_{1.36} \mathrm{Al}_{0.55} \mathrm{Fe}_{0.08}\right)_{2} \mathrm{O}_{4}$ and the corresponding molecular formula was found:

$$
\begin{aligned}
& \therefore\left(M_{0.44} F e_{0.55}\right)\left(C r_{1.36} A l_{0.55} F_{0.08}\right)_{2} O_{4} \\
& =\mathrm{Mg}_{0.44} \mathrm{O}_{0.44} \cdot \mathrm{Fe}_{0.55} \mathrm{O}_{0.55} \cdot \mathrm{Cr}_{1.36} \mathrm{O}_{2.04} \cdot \mathrm{Al}_{0.55} \mathrm{O}_{0.83} \cdot \mathrm{Fe}_{0.08} \mathrm{O}_{0.11} \\
& =\mathrm{Mg}_{44} \mathrm{O}_{44} \cdot \mathrm{Fe}_{55} \mathrm{O}_{55} \cdot \mathrm{Cr}_{136} \mathrm{O}_{204} \cdot \mathrm{Al}_{55} \mathrm{O}_{83} \cdot \mathrm{Fe}_{8} \mathrm{O}_{11} \\
& =\mathrm{Mg}_{44} \mathrm{Fe}_{63} \mathrm{Cr}_{136} \mathrm{Al}_{55} \mathrm{O}_{397}
\end{aligned}
$$

This formula can now be used in the reduction reaction. 


\section{Additional examples of matrices of minors}

Assuming different starting matrices $\mathrm{A}$ and the corresponding augmented matrices $\mathrm{B}$ :

2x2 square matrix:

$$
B=\left[\begin{array}{ccc}
a_{11} & a_{12} & 0 \\
a_{21} & a_{22} & 1 \\
0 & 1 & 0
\end{array}\right] \rightarrow M=\left[\begin{array}{ccc}
-1 & 0 & a_{21} \\
0 & 0 & a_{11} \\
a_{12} & a_{11} & a_{11} a_{22}-a_{12} a_{21}
\end{array}\right]
$$

Applications: Simple synthesis reactions: $A_{a}+B_{b} \rightarrow A_{o} B_{p}$ e.g. $2 \mathrm{H}_{2}+\mathrm{O}_{2} \rightarrow 2 \mathrm{H}_{2} \mathrm{O}$.

2x3 non-square matrix:

$$
B=\left[\begin{array}{ccc}
a_{11} & a_{12} & a_{13} \\
a_{21} & a_{22} & a_{23} \\
0 & 1 & 0
\end{array}\right] \rightarrow M=\left[\begin{array}{ccc}
-a_{23} & 0 & a_{21} \\
-a_{13} & 0 & a_{11} \\
a_{12} a_{23}-a_{13} a_{22} & a_{11} a_{23}-a_{13} a_{21} & a_{11} a_{22}-a_{12} a_{21}
\end{array}\right]
$$

Applications: Addition reactions $A_{a} B_{b}+C_{c} \rightarrow A_{o} B_{p} C_{q}$ e.g. $C_{2} H_{4}+B_{2} \rightarrow C_{2} H_{4} B r_{2}$

\section{$\underline{3 \mathrm{x} 4 \text { non-square matrix: }}$}

$$
\begin{gathered}
B=\left[\begin{array}{cccc}
a_{11} & a_{12} & a_{13} & a_{14} \\
a_{21} & a_{22} & a_{23} & a_{24} \\
a_{31} & a_{32} & a_{33} & a_{34} \\
0 & 0 & 0 & 1
\end{array}\right] \\
M=\left[\begin{array}{cccc}
a_{22} a_{33}-a_{23} a_{32} & a_{21} a_{33}-a_{23} a_{31} & a_{21} a_{32}-a_{22} a_{31} & 0 \\
a_{12} a_{33}-a_{13} a_{32} & a_{11} a_{33}-a_{13} a_{31} & a_{11} a_{32}-a_{12} a_{31} & 0 \\
a_{12} a_{23}-a_{13} a_{22} & a_{11} a_{23}-a_{13} a_{21} & a_{11} a_{22}-a_{12} a_{21} & 0 \\
a_{12}\left(a_{23} a_{34}-a_{24} a_{33}\right)- & a_{11}\left(a_{23} a_{34}-a_{24} a_{33}\right)- & a_{11}\left(a_{22} a_{34}-a_{24} a_{32}\right)- & a_{11}\left(a_{23} a_{33}-a_{23} a_{32}\right)- \\
a_{13}\left(a_{22} a_{34}-a_{24} a_{32}\right)+ & a_{13}\left(a_{21} a_{34}-a_{24} a_{31}\right)+ & a_{12}\left(a_{21} a_{34}-a_{24} a_{31}\right)+ & a_{12}\left(a_{21} a_{33}-a_{23} a_{31}\right)+ \\
a_{14}\left(a_{21} a_{33}-a_{23} a_{31}\right) & a_{14}\left(a_{21} a_{33}-a_{23} a_{31}\right) & a_{14}\left(a_{21} a_{32}-a_{22} a_{31}\right) & a_{13}\left(a_{21} a_{32}-a_{22} a_{31}\right)
\end{array}\right]
\end{gathered}
$$

Applications: Reduction of metal oxides $\mathrm{M}_{a} \mathrm{O}_{b}+R_{c} \rightarrow \mathrm{M}+\mathrm{R}_{o} \mathrm{C}_{p}$ e.g. $\mathrm{Fe}_{2} \mathrm{O}_{3}+3 \mathrm{C} \rightarrow 2 \mathrm{Fe}+3 \mathrm{CO}$

At this point we will switch over to using real and hypothetical reaction equations with numerical coefficients since the size of the matrices using only variable like the ones above, quickly span multiple pages. However, note that the last row of the minor of B still only contains elements from the original matrix A. 
Hypothetical reaction:

$$
\begin{gathered}
x_{1} A_{2} B_{3} C_{1}+x_{2} D E_{2} F \rightarrow x_{3} A_{12} B_{12} C_{10}\left(D E_{2} F\right)_{2}+x_{4} A_{4} B_{9} \\
B=\left[\begin{array}{ccccccc}
2 & 0 & -12 & -4 & 0 & 0 & 0 \\
3 & 0 & -12 & -9 & 0 & 0 & 0 \\
1 & 0 & -10 & 0 & 0 & 0 & 1 \\
0 & 1 & -2 & 0 & 0 & 1 & 0 \\
0 & 2 & -4 & 0 & 0 & 0 & 0 \\
0 & 1 & -2 & 0 & 1 & 0 & 0 \\
0 & 0 & 0 & 1 & 0 & 0 & 0
\end{array}\right] \rightarrow E=\left[\begin{array}{lllllll}
120 & 24 & 12 & 24 & 0 & 0 & 0
\end{array}\right]
\end{gathered}
$$

Therefore ,we have $10 A_{2} B_{3} C_{1}+2 D E_{2} F \rightarrow A_{12} B_{12} C_{10}\left(D E_{2} F\right)_{2}+2 A_{4} B_{9}$

$\underline{\text { Combustion of octane: }}$

$$
\begin{gathered}
x_{1} \mathrm{C}_{8} \mathrm{H}_{18}+x_{2} \mathrm{O}_{2} \rightarrow x_{3} \mathrm{CO}_{2}+x_{4} \mathrm{H}_{2} \mathrm{O} \\
B=\left[\begin{array}{cccc}
8 & 0 & -1 & 0 \\
18 & 0 & 0 & -2 \\
0 & 2 & -2 & -1 \\
0 & 0 & 0 & 1
\end{array}\right] \rightarrow E=\left[\begin{array}{llll}
4 & 50 & 32 & 36
\end{array}\right]
\end{gathered}
$$

Therefore, we have $2 \mathrm{C}_{8} \mathrm{H}_{18}+25 \mathrm{O}_{2} \rightarrow 16 \mathrm{CO}_{2}+18 \mathrm{H}_{2} \mathrm{O}$

$\underline{\text { Redox reaction involving potassium ferrocyanide: }}$

$$
\begin{aligned}
& x_{1} \mathrm{~K}_{4} \mathrm{Fe}(\mathrm{CN})_{6}+x_{2} \mathrm{KMnO}_{4}+x_{3} \mathrm{H}_{2} \mathrm{SO}_{4} \rightarrow x_{4} \mathrm{KHSO}_{4}+x_{5} \mathrm{Fe}_{2}\left(\mathrm{SO}_{4}\right)_{3}+x_{6} \mathrm{MnSO}_{4}+x_{7} \mathrm{HNO}_{3}+x_{8} \mathrm{CO}_{2}+x_{9} \mathrm{H}_{2} \mathrm{O} \\
& B=\left[\begin{array}{ccccccccc}
4 & 1 & 0 & -1 & 0 & 0 & 0 & 0 & 0 \\
1 & 0 & 0 & 0 & -2 & 0 & 0 & 0 & 0 \\
6 & 0 & 0 & 0 & 0 & 0 & 0 & -1 & 0 \\
6 & 0 & 0 & 0 & 0 & 0 & -1 & 0 & 0 \\
0 & 1 & 0 & 0 & 0 & -1 & 0 & 0 & 0 \\
0 & 4 & 4 & -4 & -12 & -4 & -3 & -2 & -1 \\
0 & 0 & 2 & -1 & 0 & 0 & -1 & 0 & -2 \\
0 & 0 & 1 & -1 & 1-3 & -1 & 0 & 0 & 0 \\
0 & 0 & 0 & 0 & 0 & 0 & 0 & 0 & 1
\end{array}\right] \rightarrow E=\left[\begin{array}{lllllllll}
10 & 122 & 299 & 162 & 5 & 122 & 60 & 60 & 188
\end{array}\right]
\end{aligned}
$$

Therefore, we have:

$$
\begin{gathered}
10 \mathrm{~K}_{4} \mathrm{Fe}(\mathrm{CN})_{6}+122 \mathrm{KMnO}_{4}+299 \mathrm{H}_{2} \mathrm{SO}_{4} \\
\downarrow \\
162 \mathrm{KHSO}_{4}+5 \mathrm{Fe}_{2}\left(\mathrm{SO}_{4}\right)_{3}+122 \mathrm{MnSO}_{4}+60 \mathrm{HNO}_{3}+60 \mathrm{CO}_{2}+188 \mathrm{H}_{2} \mathrm{O}
\end{gathered}
$$

